\title{
A ADOÇÃO DO PENSAMENTO SISTÊMICO NA GESTÃO PÚBLICA: UMA MUDANÇA DE PARADIGMA
}

\section{ARTIGO DE REVISÃO}

REBELO, Michele Alves Correa ${ }^{1}$

REBELO, Michele Alves Correa. A adoção do pensamento sistêmico na Gestão Pública: uma mudança de paradigma. Revista Científica Multidisciplinar Núcleo do Conhecimento. Ano 04, Ed. 10, Vol. 01, pp. 45-63. Outubro de 2019. ISSN: 24480959, Link de

acesso: https://www.nucleodoconhecimento.com.br/administracao/pensamentosistemico

\section{RESUMO}

Diante do atual cenário político brasileiro e frente às mudanças no panorama da gestão pública no século XXI, este artigo tem por objetivo apresentar os reflexos da adoção do pensamento sistêmico pelo gestor público evidenciando a influência que esse pensamento possa ter na tomada de decisões. Depreende-se de uma pesquisa de natureza aplicada, de objetivo exploratório, com a adoção da pesquisa bibliográfica. Trata-se de um assunto importante, devido à dificuldade do gestor público atingir a eficiência na execução das atividades administrativas. Com a pesquisa foi possível constatar que o pensamento sistêmico do gestor influencia o rumo da gestão pública, os benefícios desta postura poderão ser visíveis nos serviços prestados à sociedade e nas ações internas da instituição. Atualmente, observa-se a pessoalidade na tomada de decisões, em razão da influência política estatal e por se tratar de um cenário altamente competitivo, onde a vaidade pessoal e a cultura do imediatismo prevalecem. O pensamento sistêmico contribui para que novas visões

\footnotetext{
${ }^{1}$ Mestre em Gestão de Políticas Públicas - UNIVALI. Especialista em Direito Penal e Processual - Escola da Magistratura de Santa Catarina. Especialista em Gestão de Segurança Pública - UNIVALI. Graduação em Direito - FEBE.
} 
emergentes tornem-se compartilhadas e colaborativas. A gestão pública carece de inovação sistemática do pensar para assim atender às carências sociais e atingir a eficiência.

Palavras-chave: Gestão Pública, Gestor Público, princípio da eficiência, pensamento sistêmico.

\section{INTRODUÇÃO}

Propõe-se a presente pesquisa demonstrar aos leitores os reflexos da adoção do pensamento sistêmico pelo gestor público e como isto pode influenciar na vida das pessoas.

Desde a década de 80 observa-se um movimento crescente em busca de técnicas modernas e eficientes de gestão, capazes de proporcionar melhorias nos serviços públicos (KETTL, 2005; PAULA, 2005; MANNING et al., 2009). Em paralelo a esta realidade, o gestor público passou a se deparar com um novo ambiente global, novas exigências sociais, novas tecnologias e conceitos de projetos.

Por conta destes fatores, a forma de administrar os serviços públicos vem se transformando. O modelo burocrático está sendo substituído pelo gerencial e as mudanças políticas, sociais e culturais passam a interferir no modo de pensar da sociedade.

Em que pese este avanço nos conceitos de gestão e administração pública, vislumbrase a dificuldade do gestor público atingir a eficiência na execução de suas atividades. Tal fato se dá pela priorização dos interesses particulares dos indicados aos cargos de direção, chefia e assessoramento, bem como pela influência política sobre a tomada de decisão dos gestores públicos.

Conforme Câmara (2009), a função de direção, viabilizada mediante acesso ao cargo público classificado como de livre provimento, implica expectativas de desempenho do cargo associadas aos interesses políticos de quem tem o poder de nomear. Por tal 
razão exige-se lealdade pessoal do nomeado. Trata-se de um vínculo precário, podendo ser exonerado a qualquer momento.

$\mathrm{Na}$ tradição administrativa brasileira, apenas o núcleo mais técnico do Estado tende a ter os cargos de alta direção preservados de nomeações marcadamente políticas (FLEURY, 2009).O ideal seria que estes cargos fossem ocupados por pessoas que tivessem conhecimento técnico. No entanto, adota-se na maioria dos casos, critério subjetivo de nomeação.

O foco deste trabalho é justamente buscar uma reflexão sobre uma nova postura do gestor público frente a esta problemática. Será necessário abordar de forma perfunctória, aspectos de cunho subjetivo, como o caráter do gestor, que determina 0 comportamento moral ou social e, por conseguinte, o rumo de uma boa ou má gestão.

A gestão pública carece de novas posturas de poder e liderança. Uma inovação sistêmica do pensar deve ocorrer em todo e qualquer ponto da instituição. Trata-se não apenas de fazer coisas diferentes, mas fazer as mesmas coisas de formas diferentes, criando, como refere Peter Drucker (2002), novos potenciais de satisfação.

Diante da complexidade do tema e a partir de uma análise sistemática, temos o direito e o gestor como sistemas abertos, que se relacionam em uma sintonia dinâmica. Estão em processo contínuo e incessante de trocas e intercâmbio com o ambiente. As organizações são sistemas de papéis desempenhados pelas pessoas (CHIAVENATO, 2000).

Sob a visão e contribuição das ciências sociais, verifica-se a possibilidade de se realizar a pesquisa fundamentada na teoria de Bertalanffy (1937), que possui uma visão diferente do reducionismo científico até então aplicada pela ciência convencional.

Conforme Valença (2011), a abordagem sistêmica está diretamente associada à leitura da complexidade do raciocínio, do domínio ou da superveniência da emoção nas decisões humanas e dos estímulos à decisão eficaz. 
Pensar sistematicamente é pensar a complexidade, a instabilidade e a intersubjetividade. Um profissional que vive - vê o mundo e atua nele - as implicações de ter assumido para si os pressupostos citados, pode ser considerado um profissional sistêmico. Deve ter o olhar do observador - o observador como parte do sistema (VASCONCELOS, 2009).

Com o tema delineado, propõe-se demonstrar os reflexos da adoção do pensamento sistêmico e as influências que esta postura pode gerar na vida das pessoas, respondendo a seguinte indagação: será possível atingir a eficiência com a adoção do pensamento sistêmico pelo gestor público?

Para atingir o objetivo proposto será utilizado o método descritivo por meio de pesquisa bibliográfica.

Para Fonseca (2002), a pesquisa bibliográfica é feita a partir do levantamento de referências teóricas já analisadas, e publicadas por meios escritos e eletrônicos, como livros, artigos científicos e páginas de web sites.

No próximo capítulo será apresentado o conceito de gestão pública e, em item específico, o gestor. Em seguida, abordar-se-á, de forma perfunctória, o princípio da eficiência. E, por fim, apresentar-se-á o pensamento sistêmico e as reflexões sobre este olhar na construção de um novo paradigma de gestão pública.

\section{GESTÃO PÚBLICA}

Nos últimos 30 anos o termo "gestão pública" vem sendo utilizado em substituição à administração pública e, por tal razão, tem sido considerado um termo polissêmico, visto que parte da doutrina entende que os dois termos se confundem. Outros defendem que houve o rompimento do conceito tradicional, pelo fato de abranger ferramentas de gestão do mundo empresarial e, portanto, um conceito mais amplo.

Henri Fayol (1950), já na década de 50, definia a gestão como funções administrativas de prever, organizar, comandar, coordenar e controlar. 
Desde a década de 80, os governos de diversos países, têm empreendido esforços para modernizar a administração pública com o objetivo de reduzir o alcance do governo e fazê-lo funcionar melhor, na busca da agilidade. A própria avaliação da administração pública se altera, passando a ser balizada por critérios próximos àqueles utilizados pela administração privada.

Em decorrência desta postura surge a New Public Manegement (NPM), associada ao contexto de uma específica reforma do Estado, cujo modelo contrapõe-se ao convencional de administração pública, baseado na burocracia weberianeferido modelo consiste em conferir um enfoque gerencial, inspirado nos métodos de gestão dos negócios privados, à administração pública (HOOD, 1995; HERNES, 2005), de forma a assegurar maior responsividade e melhor desempenho na provisão de serviços públicos à população (MANNING et al., 2009).

Perry e Kraemer (1983) consideram que a gestão pública é uma fusão da orientação normativa da administração pública tradicional e da orientação instrumental da gestão, em um sentido genérico. Ou seja, no primeiro aspecto, a gestão pública incorpora temas como democracia e responsabilidade, e valores como equidade, igualdade e probidade. E no segundo, uma orientação instrumental, com a ideia de que o setor público compartilha com o privado a necessidade de alcançar seus objetivos de forma mais econômica e eficiente.

Para Druker (1993) gestão não se refere à hierarquia organizativa de uma administração clássica, mas a capacidade de promover a inovação sistemática do saber e tirar dela o máximo rendimento na sua aplicação à produção.

Diferentemente da gestão privada, a gestão pública deve orientar-se a partir de valores sociais. Assume-se aqui, a concepção de que gestão é um ato complexo que nos aproxima do mundo da política (BRUGUÉ; SUBIRATS, 1996).

Pensar na evolução histórica da gestão pública, de forma prospectiva, remete a uma reflexão sobre o verdadeiro papel do Estado na atualidade. Gerenciar o que é público é um ato complexo e desafiador, pois o cenário é altamente competitivo. Prevalecem 
neste meio a vaidade pessoal e a cultura do imediatismo. A cada legislatura a dinâmica da administração é alterada. Não há continuidade de ações em razão da pessoalidade na tomada de decisões, tendo em vista a influência política que assola o país.

As pessoas ficam aterrorizadas com as notícias de crimes bárbaros que são veiculadas na mídia. No entanto, não se dão conta de que uma obra superfaturada ou inacabada, por consequência da má gestão, pode ter contribuído para o caos na educação e na saúde de determinada região.

Cardoso Jr (2001) argumenta que ao Estado cabe não apenas fazer as coisas de modo melhor e mais eficiente. Mais do que isto, cabe-lhe a tarefa de induzir, fomentar ou mesmo produzir as condições para a transformação das estruturas econômicas e sociais do país. O processo envolve o redesenho da estrutura, procedimentos e práticas do setor público, incorporando mudanças de grande magnitude na dimensão institucional, onde se incluem questões atinentes aos princípios e valores que informam a relação de tais organizações com a sociedade e o mercado (FERLIE et al., 1999; ORMOND; LOFFLER, 1999; HERNES, 2005).

Neste sentido, a gestão pública carece de inovação sistêmica para assim atender às carências sociais e atingir a eficiência. A adoção do pensamento sistêmico pelo gestor poderá contribuir para que novas visões emergentes se tornem visões compartilhadas e colaborativas. A visão do todo é fundamental para a tomada de decisões.

Para Abrúcio (2007), a gestão pública tem uma série de peculiaridades que dizem respeito à necessidade de se ter instrumentos gerenciais e democráticos para combater os problemas que o Estado enfrenta no mundo contemporâneo. Nesse contexto, o formalismo e a rigidez burocrática devem ser atacados como males, e a meritocracia pode promover a modernização.

A visão compartilhada é o primeiro passo para conseguir que pessoas que não confiam umas nas outras comecem a trabalhar em conjunto. Cria uma identidade comum. (SENGE,2009). Por meio de uma cultura do feedback, a relação de confiança 
na equipe e o reconhecimento do esforço contribuem para a eficiência da gestão pública, pois atinge o aspecto relacionado à motivação.

O gestor pode transformar os conceitos (pré) estabelecidos ao longo da história. Em que pese estar atrelado ao princípio da legalidade, poderá fazer a diferença. Para isto deve assumir uma nova postura, o olhar sistêmico na busca da eficiência, cujos conceitos e aspectos serão abordados a seguir.

\subsection{GESTOR PÚBLICO}

Segundo o conceito clássico desenvolvido por Henri Fayol (1950), o gestor é definido pelas suas funções na organização. É a pessoa a quem compete a interpretação dos objetivos propostos pela instituição e atua por meio do planejamento, a fim de atingir as metas e objetivos.

Pode-se dizer então que o gestor é alguém que desenvolve o plano estratégico e operacional, julga os meios eficazes, concebe as estruturas e estabelece as regras políticas e procedimentos mais adequados e, por fim, implementa e coordena a execução dos projetos por meio de um determinado tipo de comando (ou liderança).

Para Chiavenato (2004) ser gestor ou líder é ter uma visão global, uma relação entre o homem e o seu ambiente de trabalho. Além disso, é saber ensinar e aprender, sendo este último de vital importância. Partindo para uma premissa mais subjetiva, Peter Drucker (1993) afirma que é através do caráter que se exerce a liderança. Na mesma linha de pensamento, Havard (2011) define que a virtude, além de ser um valor intrínseco do ser humano, é uma força dinâmica que aumenta a capacidade de ação, característica tão necessária ao líder. A virtude gera confiança, e sem confiança tornase impossível liderar.

Ser gestor público é um desafio, pois gerenciar algo que é público é um ato complexo em razão do cenário político altamente competitivo. Em face às frequentes manchetes veiculadas na mídia de corrupção, desvios de verbas públicas, estabeleceu-se um paradigma de que os serviços públicos não atendem à sociedade de forma eficiente. 
A cada legislatura a dinâmica da administração é alterada, ocorrendo mudanças radicais. Este processo é salutar, pois do contrário haveria a ditadura ou a monarquia. No entanto, é necessária uma continuidade das ações e projetos. É muito importante que o gestor tenha ciência e a noção do quão é importante a mudança de postura na execução das tarefas diárias e como esta atitude pode transformar a vida das pessoas. Uma decisão acertada pode significar educação para as crianças carentes de determinada região. Mais do que nunca, a sociedade clama por resultados diferentes. É preciso rever o processo tradicional de pensar o serviço público e implementar novas atitudes.

O gestor público da mesma forma que na iniciativa privada necessita de características e qualidades que the habilitem a promover as mudanças que são propostas. Sendo os líderes no setor público, os gestores precisam ser dotados de conhecimentos, habilidades e atitudes, além de uma forte vocação para lidar com as diversas formas e fontes de poder que permeiam o setor público (MORGAN, 1996).

A adoção do pensamento sistêmico está intimamente ligada ao desenvolvimento das virtudes éticas do gestor e/ou líder. Podemos relacionar algumas características com as vertentes sistêmicas, a saber: liderança voltada a cooperação e influenciação, a comunicabilidade com ênfase nos relacionamentos, o humanitarismo com ênfase no processo, o pensamento em rede, flexibilidade, visão ampla com totalidade e dinamicidade (ANDRADE, 2016).

A ação de administrar é vinculada à prática do pensamento sistêmico e da alavancagem estratégica. As características da liderança, no contexto da interação humana que privilegia os processos de otimização da aprendizagem, estão voltadas para o exercício da participação em todos os níveis e para a construção de equipes (ZANELLI,2008).

A ideia da ineficácia dos serviços públicos deve ser abandonada e a influência política reduzida. É preciso compreender que se a atenção estiver voltada para uma parte isolada visando interesses restritos, não será possível perceber todo o sistema, sendo 
fundamental pensar no todo e não nas fases, se quiser corrigir rumos e atingir a eficiência, cuja temática será apresentada no tópico a seguir.

\section{PRINCÍPIO DA EFICIÊNCIA}

Inicialmente, faz-se necessário estabelecer que os princípios administrativos são diretrizes basilares que fundamentam e respaldam a maneira de operar dos agentes públicos, quando da efetivação das atribuições vinculadas à administração pública.

O princípio da eficiência, previsto no art. 37 da CF de 1988, teve sua origem no direito privado, sendo inserido na administração pública, na reforma administrativa.

A eficiência no setor público é uma exigência da nova tendência mundial em atender os interesses coletivos de forma célere e com resultados efetivos. Busca-se um Estado que planeje, desenvolva e execute suas funções com efetividade, fazendo uso de novas técnicas e hábitos que visem resultados satisfatórios.

O princípio da eficiência pode ser compreendido em dois vieses: primeiro em relação ao modo de atuação do agente público, do qual se espera o melhor desempenho possível de suas atribuições, visando os melhores resultados e, segundo, em relação ao modo de organizar, estruturar e disciplinar a Administração Pública, também com o objetivo de alcançar os melhores resultados na prestação do serviço público (DI PIETRO, 2014).

A atividade administrativa deve ser conduzida por gestores comprometidos e preocupados com a efetividade na prestação de serviços públicos. A principal característica do gestor deve ser o pensamento sistêmico, como forma de visualizar todo o processo. Uma gestão eficiente tem como vertente o desenvolvimento social. Por isso, o principal objetivo do gestor deve estar relacionado com a utilização dos melhores meios de atingir a satisfação das necessidades coletivas.

A mudança de postura está atrelada à nova visão dos gestores e dos cidadãos em relação à administração da coisa pública. É necessário desapegar da visão ultrapassada de que o interesse do Estado se sobrepõe ao interesse privado. 
O constitucionalismo moderno não só posicionou o homem no epicentro do ordenamento jurídico, garantindo proteção diferenciada aos direitos fundamentais individuais, como também tutelou interesses de cunho coletivo, que ultrapassam a esfera individual, no intuito de possibilitar o próprio gozo dos direitos por todos os integrantes da comunidade política (BINENBOJM,2010).

O termo interesse público deve ser interpretado como a máxima realização de todos os interesses, individuais e coletivos, protegidos juridicamente. No atual Estado Democrático de Direito, os direitos fundamentais da sociedade se sobrepõem e sua satisfação deve ser buscada pelo Estado acima que qualquer outro interesse.

A falta de controle da sociedade sobre o Estado, ainda dominado por interesses particulares, é apontado como um fator negativo na gestão pública. Para Filho (2005), a preservação da esfera privada do indivíduo em conjunto com a promoção dos anseios da comunidade política representa o verdadeiro interesse público a ser perseguido pela Administração.

Para que a eficiência melhore significativamente é necessário não apenas a democratização do sistema político, mas a inclusão de mecanismos democráticos internos à administração pública, que estejam relacionados com a formação das políticas públicas e o compartilhamento de poder na tomada de decisões.

Os gestores públicos, cidadãos e outros atores fazem parte de um sistema dinâmico, aberto e interativo de governança, onde a autoridade do Estado é utilizada de diferentes formas para alcançar vários resultados públicos.

Neste contexto, a participação da sociedade tem valor imensurável, na medida em que incentiva uma cidadania ativa. $\mathrm{O}$ empoderamento das comunidades e o espírito cívico podem fazer a diferença na gestão pública e, por conseguinte, nos resultados dos serviços públicos entregues pelo Estado.

Por outro lado, o gestor público deve refletir suas ações, sob a égide do pensamento sistêmico, cujo tema será abordado a seguir. 


\section{PENSAMENTO SISTÊMICO}

Através do ato de pensar, os seres humanos modelam o mundo, interagindo de acordo com seus desejos, planos e metas. Podem ser associados ao pensamento os conceitos e processos de cognição, senciência, consciência e imaginação (ANDRADE, 2016). Com foco na evolução da ciência, podem-se citar como predominantes os pensamentos cartesiano, complexo e sistêmico.

O pensamento sistêmico surgiu no século $X X$, contrapondo-se ao pensamento reducionista-mecanicista de Descartes e Newton, o qual é fundamentado no paradigma da ciência tradicional referida por Vasconcellos (2009), cujos pressupostos basilares se resumem na simplicidade, estabilidade e objetividade.

O pressuposto da simplicidade está baseado na crença em que é preciso separar as partes para entender o todo. Neste olhar, Cunha (2006) interpreta que a redução é outra operação em busca da simplicidade, que unifica o que é diverso. Ao encontrar um fenômeno complexo, o cientista busca sua redução a outro fenômeno mais simples e já bem mais compreendido.

O pressuposto da estabilidade reside na crença em que há uma estabilidade no mundo e nele há repetições com regularidade. No âmbito do pressuposto da objetividade, constitui-se a crença de que é possível conhecer o mundo como ele compõe-se na realidade, tratando-se do critério essencial do pensamento científico (CUNHA, 2006).

O paradigma da ciência tradicional, através do pensamento linear-cartesiano se desenvolveu e se estabeleceu nas ciências físicas e exatas, tornando-se modelo de cientificidade. Os físicos atuavam baseados nos pressupostos da simplicidade, estabilidade e objetividade, e obtinham sucesso, explicando o mundo físico e desenvolvendo tecnologias sofisticadas que modificavam cada vez mais as relações do homem com a natureza (VASCONCELLOS, 2009). 
Com as convicções de que existe diferença entre o ser humano e a natureza, e que os fenômenos humanos são de natureza subjetiva, estabeleceu-se a ruptura entre ciências da natureza (objetivas) e ciências do homem. Segundo Vasconcellos (2009), as ciências físicas adotaram facilmente os três pressupostos epistemológicos. As ciências biológicas adotaram o pressuposto da objetividade, e tiveram problemas com os da simplicidade e estabilidade, enquanto as ciências humanas tiveram dificuldades em relação aos três pressupostos, em especial, o da objetividade.

O pensamento sistêmico propõe, em contraposição, os paradigmas da complexidade, da instabilidade e da intersubjetividade, que se integram incrivelmente com a psicologia analítica de Carl Gustav Jung (VASCONCELLOS, 2009).

Um profissional que vive, vê o mundo e atua nele as implicações de ter assumido para si os pressupostos da complexidade, instabilidade e intersubjetividade pode ser considerado um profissional sistêmico (VASCONCELLOS, 2009).

O paradigma sistêmico, que considera os pressupostos de complexidade, subjetividade, instabilidade, tem como princípios a flexibilidade e a plasticidade que se manifestam nos sistemas por meio de características auto-organizativas que, a partir do caos, assume aspectos de autorrenovação e autotranscedência. Desta forma, os sistemas abertos longe do equilíbrio podem se preservar, reproduzir-se, renovar-se, adaptar-se e evoluir. Assim ficam evidentes os processos de adaptação de um lado e do outro, os de aprendizagem, de desenvolvimento e evolução (COSTA, 2007).

Cunha (2006) expressa a noção de que o pensamento sistêmico significa pensar em termos de conexões, relações, contexto, interações dos elementos de um todo; de ver coisas em termos de redes, teias e comunidades.

O pensamento sistêmico não nega a racionalidade científica, mas acredita que ela não oferece parâmetros suficientes para o desenvolvimento humano e para descrição do universo material. Por tal razão, busca o olhar no sentido contrário do reducionismo, dando maior ênfase ao todo do que à parte. 
Pressupõe uma metodologia de pensar em processos, que configuram a existência do todo. Ou seja, é necessário estudar os sistemas globalmente, de forma a envolver todas as suas interdependências, pois cada um dos elementos, ao serem reunidos para constituir uma unidade funcional maior, desenvolvem qualidades que não se encontram em seus componentes isolados (BERTALANFFY, 2009).

Capra (1996) defende que o pensamento fragmentado não é capaz de tratar a interconexão dos problemas globais, tanto nos níveis maiores da sociedade como no nível individual. Neste sentido, a essência do pensamento sistêmico está na mudança de mentalidade, o que significa ver inter-relações ao invés de cadeias lineares de causa-efeito e ver processos de mudança ao invés de instantâneos (SENGE, 2009). Nesta cojuntura, não se deve pensar as mudanças como ações isoladas, mas como um conjunto de medidas interdependentes que fazem parte do planejamento de melhorias da organização.

Trata-se de uma forma de analisar e pensar o conhecimento sobre o mundo, por meio de sistemas. Uma visão sistêmica ou o "pensar sistêmico" significa ter em mente o que se deseja resolver, escolhendo a maneira certa ou a mais adequada. Pode-se dizer que se trata de uma habilidade que um indivíduo adquire para analisar os eventos e suas possíveis consequências, com o objetivo de criar uma solução única que contemple as expectativas de todas as partes envolvidas.

Tanto na iniciativa privada quanto na gestão pública não há uma uniformidade pela adoção do pensamento sistêmico pelos gestores. A maioria dos agentes públicos sequer conhece o conceito. Pode-se reafirmar a importância do pensamento sistêmico na gestão através das palavras de Zanelli:

A ação de administrar é vinculada à prática do pensamento sistêmico $e$ da alavancagem estratégica. As características da liderança, no contexto da interação humana que privilegia os processos de otimização da aprendizagem, estão voltadas para o exercício da participação em todos os níveis e para a construção de equipes (ZANELLI,2008, p. 13).

Em 2008, a Fundação Nacional de Qualidade (FNQ), presente nos mais prestigiados modelos mundiais de excelência, realizou uma pesquisa virtual com 196 executivos 
brasileiros. Os resultados revelaram que a maioria dos entrevistados conhecia apenas de forma parcial o conceito de Pensamento Sistêmico.

A grande preocupação dos cientistas sistêmicos é o reconhecimento de que a necessidade de uma profunda mudança de percepção e de pensamento, para garantir a sobrevivência, ainda não atingiu a maioria dos gestores, nem os administradores e os professores das nossas grandes universidades (CAPRA, 1996).

Quando as pessoas percebem o mundo de forma diferente, surgem novas crenças e premissas, que possibilita o desenvolvimento de novas habilidades e capacidades, formando um ciclo contínuo de aprendizado organizacional.

Peter Senge (2009) coloca que o pensamento sistêmico pode ser apresentado como uma disciplina, um estudo com teoria e prática, que permite desenvolver a visão de conjunto, uma estrutura para ver as inter-relações em lugar de coisas, para ver padrões de mudança em lugar de 'instantâneos' estáticos. O gestor, na medida que adota o pensamento sistêmico, poderá fazer a diferença na gestão pública e mudar a realidade do país. Com este novo olhar, poderá conduzir as ações da instituição, interpretando políticas e procedimentos e adequando os processos e as práticas internas aos requisitos definidos em lei.

É preciso inovação na gestão pública. O gestor tem que assumir o papel e deixa de atuar como mero coadjuvante, executando as tarefas com coragem. Pensar sistematicamente em prol do bem-estar social.

Trata-se de um tema complexo, pelo fato de que a mudança de postura do gestor, em adotar o pensamento sistêmico no exercício da gestão, estar relacionado a critérios subjetivos, como o caráter, cuja virtude não é mensurada ou avaliada quando do ingresso deste profissional na atividade pública, independentemente de ter sido por concurso público ou nomeação por indicação.

No entanto, como apresentado na pesquisa, a gestão pública está em crescente avanço, ampliando a capacidade política do Estado para "fazer bem a política" para melhor atender a sociedade e, por conseguinte, atingir a eficiência. Cada vez mais 
autores defendem o abandono teórico do princípio da supremacia. Interesses públicos e interesses privados claramente não são categorias antagônicas, mas sim complementares (JUSTEN FILHO, 2005).

A pesquisa permitiu inferir que a aplicação dos conceitos do pensamento sistêmico pode agregar valor significativo a diversas áreas de pesquisa e em setores nas organizações. Neste sentido, o uso da abordagem sistêmica em outras áreas pode se revelar como contribuição acadêmica relevante.

Assim, é válido afirmar que o objetivo deste estudo foi atingido, sendo possível afirmar que a adoção do pensamento sistêmico pelo gestor está relacionado diretamente ao princípio da eficiência.

Para trabalhos futuros, propõe-se a realização de pesquisas em órgãos da administração pública, com o objetivo de verificar as características comportamentais sistêmicas dos gestores, sugerindo práticas à gestão sistêmica com foco no comportamento das pessoas.

\section{CONSIDERAÇÕES FINAIS}

Após análise dos documentos encontrados na literatura, foi possível identificar que a adoção do pensamento sistêmico pelo gestor pode influenciar o rumo da gestão pública do país. Trata-se de uma habilidade que um indivíduo adquire para analisar os eventos e suas possíveis consequências, com o objetivo de criar uma solução única que contemple as expectativas de todas as partes envolvidas. Os benefícios desta nova visão/postura poderão ser visíveis nos serviços prestados à sociedade e nas ações internas da instituição, pelo fato de estar diretamente relacionado à tomada de decisões.

Para tanto, o gestor público, da mesma forma que na iniciativa privada, necessita de características e qualidades que the habilitem a promover as mudanças que são propostas. Sendo os líderes do setor público, os gestores precisam ser dotados de 
conhecimentos, habilidades e atitudes, além de uma forte vocação para lidar com as diversas formas e fontes de poder que permeiam o setor público (MORGAN, 1996).

A adoção do pensamento sistêmico está intimamente ligada ao desenvolvimento das virtudes éticas do gestor. A visão de mundo é individual. Logo, não há como ter uma unidade ou controle na maneira de pensar e agir. Nesta conjuntura, não se deve pensar as mudanças como ações isoladas, mas como um conjunto de medidas independentes que fazem parte do planejamento de melhorias da organização.

O pensamento sistêmico "ajuda a entender como mudar sistemas de modo mais eficaz e como agir em melhor sintonia com os processos do mundo natural e social" (VALENÇA, 2011).

As organizações que realmente terão sucesso no futuro serão aquelas que descobrirem como cultivar nas pessoas o comprometimento e a capacidade de aprender em todos os níveis da organização (SENGE,2009).

Destarte, deve-se considerar que o presente estudo pretendeu discutir uma perspectiva ainda incipiente sobre um tema estratégico para os órgãos públicos no que se refere à gestão, sem intenção de exaurir o assunto.

\section{REFERÊNCIAS}

ABRUCIO, Fernando Luiz. Trajetória recente da gestão pública brasileira: um balanço crítico e a renovação da agenda de reformas. Edição Especial Comemorativa. Rio de Janeiro: Revista de Administração Pública (RAP), 2007.

ALVAREZ, Maria Esmeralda Ballestero. Organização, sistemas e métodos. São Paulo: McGraw-Hill, 1990.

ALVES, João Bosco da Mota. Teoria Geral de Sistemas - Em busca da interdisciplinaridade. Florianópolis. Instituto Stela, 2012. 
AMARAL, Antônio Carlos Cintra do. O princípio da eficiência no direito administrativo. Revista Diálogo Jurídico, Salvador, CAJ - Centro de Atualização Jurídica, n.14, jun./ago. 2002.

ANDRADE, A; Rodrigues, L; Seleme A; Souto, R; Pensamento sistêmico: Caderno de campo. $O$ desafio da mudança sustentada nas organizações e na sociedade. Porto Alegre: Bookman, 2006.

BINENBOJM, Gustavo. Da Supremacia do Interesse Público ao Dever de Proporcionalidade: Um novo paradigma para o Direito Administrativo. In: SARMENTO, Daniel (org.). Interesses públicos versus Interesses privados: desconstruindo o princípio da supremacia do interesse público. Rio de Janeiro: Lumen Juris, 2010.

BERTALANFFY, L. von. Teoria Geral dos Sistemas: Fundamentos, desenvolvimento e aplicações. São Paulo: Editora Fundação Perseu Abramo, 2006.

BRASIL. Constituição da republica Federativa do Brasil: 1988. 25. Ed. Brasília: Câmara dos Deputados, Coordenação de Publicações, 2012.

CÂMARA, Leonor Moreira. Fatores do Pensamento Sistêmico como Potencializadores de Sucesso de Projetos de Software no Setor Público.organização da administração pública Federal Brasileira: uma introdução ao estudo da organização da direção pública na perspectiva de estudos organizacionais. Rio de Janeiro: Revista de Administração Pública (RAP), 43(3), maio/junho 2009.

CAPRA, F. O Ponto de Mutação. A ciência, a sociedade e a cultura emergente. Trad. Álvaro Cabral, São Paulo: Cultrix, 2006.

CAPRA, Fritjof. A Teia da Vida. Uma Compreensão Cientifica dos Sistemas Vivos. São Paulo (SP). Editora Cultrix. 1997.

CARNEIRO, R., MENICUCCI, TMG. Gestão pública no século XXI: as reformas pendentes. In Fundação Oswaldo Cruz. A saúde no Brasil em 2030 - prospecção 
estratégica do sistema de saúde brasileiro: desenvolvimento, Estado e políticas de saúde [online]. Rio de Janeiro: Fiocruz/lpea/Ministério da Saúde/Secretaria de Assuntos Estratégicos da Presidência da República, 2013. Vol. 1. pp. 135-194. ISBN 978-85-8110-015-9. AvailablefromSciELO Books.

CHIAVENATO, Idalberto. Recursos Humanos. O Capital Humano das Oganizações. SãoPaulo:Atlas, 2004.

CHIAVENATO, Idalberto. Iniciação à Organizações e Controle.São Paulo: McGrawHill, 1989.

COSTA, WedjaJosefa Granja. Socionomia de base sistêmica: Método de apoio à gestão de grupos na organização. Dissertação de Mestrado. Fortaleza: Universidade Federal do Ceará, 2007.

CUNHA, Aura Celeste Santana. Pensamento Sistêmico e tecnologia educacional: a metodologia WEBQUEST. Dissertação de Mestrado Profissional em Computação. Fortaleza: Universidade Estadual do Ceará, 2006.

DRUCKER, Peter. The effective executive.Harper Collins Publishers, 1993.

DRUCKER, Peter F. Administrando para o Futuro: os anos 90 e a virada do século. Tradução de Nivaldo Montigelli Jr. São Paulo: Pioneira Thomson Learning, 2002.

FALCONI, Vicente. O verdadeiro Poder.Nova Lima: INDG Tecnologia e Serviços Ltda. 2009.

FAYOL, Henri. Administração Industrial e Geral.São Paulo. Atlas, 1990.

FLEURY, S. J. F. Redes de proteção: incentivos, escolhas e comportamentos na política brasileira. 2009. Tese (Doutorado) - Faculdade de Filosofia e Ciências Humanas da Universidade Federal de Minas Gerais, Belo Horizonte, 2009. 
HERNES, T. Four ideal-types organizational responses to the new public management reforms and some consequences. International Review of Administrative Sciences, v. 71, n. 1, p. 5-17, 2005.

HOOD, C. A public management for all seasons? Public Administration, . 69, $\mathrm{n}$. $1,1991$.

JUSTEN FILHO, Marçal. Curso de Direito Administrativo. São Paulo: Saraiva, 2005.

GOMES, Lauren Beltrão et al . As origens do pensamento sistêmico: das partes para o todo. Pensando familiar, Porto Alegre, 2014.

KOLTER, John P. Liderando Mudanças. Rio de Janeiro: Elsevier, 2013.

LAKATOS, Eva Maria; MARCONI, Mariana de Andrade. Fundamentos de Metodologia Científica. 4 ed. São Paulo: Atlas, 2001.

LIMA, Joilson Souza de. O Planejamento Estratégico como Ferramenta de Gestão. Revista Científica Multidisciplinar Núcleo do Conhecimento. Ano 03, Ed. 03, Vol. 03, pp. 58-69, Março de 2018. ISSN:2448-0959.

MEIRELLES, Hely Lopes. Direito Administrativo Brasileiro. São Paulo: Malheiros, 2002.

MANNING, N. et al. Reformas de gestão pública: o que a América Latina tem a aprender com a OCDE.In: MEDEIROS, P. C.; LEVY, E. (Orgs.). Novos caminhos da gestão pública: olhares e dilemas. Rio de Janeiro: Qualitymark; Brasília: CONSAD, 2009. p. 97-148.

MORAES, Germana de Oliveira. Controle Jurisdicional da Administração Pública. São Paulo: Dialética, 1999, p. 127.

MORGAN, Goreth. Imagens da Organização. São Paulo: Atlas, 1996. 
PIETRO, Maria Sylvia Zanella Di. Direito Administrativo. São Paulo: Atlas, 2002.

SENGE, Peter M. A quinta disciplina: arte e prática da organização que aprende. $25^{\mathrm{a}}$ ed. Rio de Janeiro: BestSeller, 2009.

SEMLER, Ricardo. Virando a própria Mesa: Uma história de Sucesso Empresarial. Rio de Janeiro, 2002.

VALENÇA, Antônio Carlos. Aprendizagem Organizacional: 123 aplicações práticas de arqueótipos sistêmicos. São Paulo:SENAC, 2011.

VASCONCELLOS, Maria José Esteves. Pensamento Sistêmico: O novo paradigma da ciência. 9aㅗ ed. Campinas-SP: Papirus,2010.

ZANELLI, José Carlos. Interação Humana e Gestão: a construção psicossocial das organizações de trabalho. São Paulo: Casa do Psicólogo, 2008.

Enviado: Outubro, 2019.

Aprovado: Outubro, 2019. 